\title{
INFLUENCE OF TEMPERATURE ON THE STRUCTURAL BEHAVIOUR OF MASONRY BUILDINGS
}

\author{
M. GIRARDI ${ }^{*}$, C. PADOVANI ${ }^{2}$ AND D. PELLEGRINI ${ }^{2}$ \\ ${ }^{1}$ Institute of Information Science and Technologies “A. Faedo”, ISTI-CNR \\ Via Moruzzi, 1, 57126 Pisa (PI) \\ e-mail: maria.girardi@isti.cnr.it, www.isti.cnr.it (*corresponding author) \\ ${ }^{2}$ Institute of Information Science and Technologies "A. Faedo", ISTI-CNR \\ Via Moruzzi, 1, 57126 Pisa (PI) \\ email: \{cristina.padovani, daniele.pellegrini\}@isti.cnr.it, www.isti.cnr.it
}

Keywords: Historical Structures, Masonry, Nonlinear analysis, Thermal loads

\begin{abstract}
This paper investigates the mechanical behaviour of heritage structures subjected to seasonal temperature variations. To this end, the constitutive equation of masonry-like materials, which has been embedded in the finite element code NOSA-ITACA (www.nosaitaca.it), is used to model the static and dynamic behaviour of simple arched masonry structures subjected to thermal loads.
\end{abstract}

\section{INTRODUCTION}

Unlike linear elastic materials whose mechanical behaviour in the presence of thermal variations has been investigated in-depth [1], masonry materials under non-isothermal conditions are scarcely explored. A first contribution in this regard was provided in [2], which studied the influence of temperature changes on the displacements and stresses of masonry bridges. More recently, finite element simulations of the static behaviour of the Basilica of San Vitale in Ravenna have been conducted [3], taking seasonal thermal variations into account. Several papers report the presence of cracks in masonry monuments and bridges, which can be ascribed to thermal fluctuations [4, 5]. Moreover, numerous experimental campaigns $[6,7,8,9,10,11]$ have demonstrated that the presence of thermal strains affects not only the static behaviour of masonry structures, but also their dynamical properties. Long-term ambient vibration monitoring on masonry towers has proved the influence of environmental parameters such as temperature and humidity on the measured natural frequencies, which generally tend to increase with temperature. Such behaviour is often attributed to the closing of micro-cracks in masonry, due to thermal expansion. Similar effects were also detected in the Mallorca Cathedral and described in [11],which reports frequencies variations on the order of $10-20 \%$.

\section{THE CONSTITUTIVE EQUATION OF NO-TENSION MATERIALS UNDER NON-ISOTHERMAL CONDITIONS}

Masonry is modelled herein as an isotropic nonlinear elastic material with zero tensile strength and infinite compressive strength [12]. This constitutive equation has been 
generalized in order to take into account the presence of thermal dilatation, the goal being to model the influence of temperature variations on the stress fields, crack distribution, and modal properties of the structure. Indeed, there are many engineering problems in which the presence of thermal dilatation must be taken into account; relevant examples range from daily and seasonal thermal variations affecting the stress field in masonry constructions, to the thermo-mechanical behaviour of masonry structures under elevated temperatures, such as the refractory linings of vessels and ladles used in the iron and steel industry.

Let us denote by $\theta \in\left[\theta_{1}, \theta_{2}\right]$ the temperature and by $\theta_{0} \in\left[\theta_{1}, \theta_{2}\right]$ the reference temperature. We assume that the thermal dilatation due to the temperature variation $\Delta \theta=\theta-$ $\theta_{0}$ is the spherical tensor $\alpha\left(\theta-\theta_{0}\right) \mathbf{I}$, where $\alpha$ is the linear coefficient of thermal expansion and $\mathbf{I}$ the identity tensor. It is possible to prove that for every infinitesimal strain tensor $\mathbf{E}$ and $\theta \in\left[\theta_{1}, \theta_{2}\right]$, there exists a unique triplet $\left(\mathbf{T}, \mathbf{E}^{e}, \mathbf{E}^{f}\right)$ of symmetric tensors such that $\mathbf{E}-$ $\alpha\left(\theta-\theta_{0}\right) \mathbf{I}$ is the sum of the elastic strain $\mathbf{E}^{e}$ and the positive semidefinite fracture strain $\mathbf{E}^{f}$, and that the Cauchy stress $\mathbb{T}$, negative semi-definite and orthogonal to $\mathbb{E}^{f}$, depends linearly and isotropically on $\mathbb{E}^{e}$, through Young's modulus $E$ and Poisson's ratio v[13]. Here, in view of the modest amplitude of the temperature range considered in the analysis, the elastic constants $E$ and $v$, which are generally functions of temperature [14], do not depend on $\theta$. T is the stress corresponding to strain $\mathbf{E}$ and temperature $\theta$, and masonry-like materials are then characterized by the stress function $\overline{\mathrm{T}}$ given by

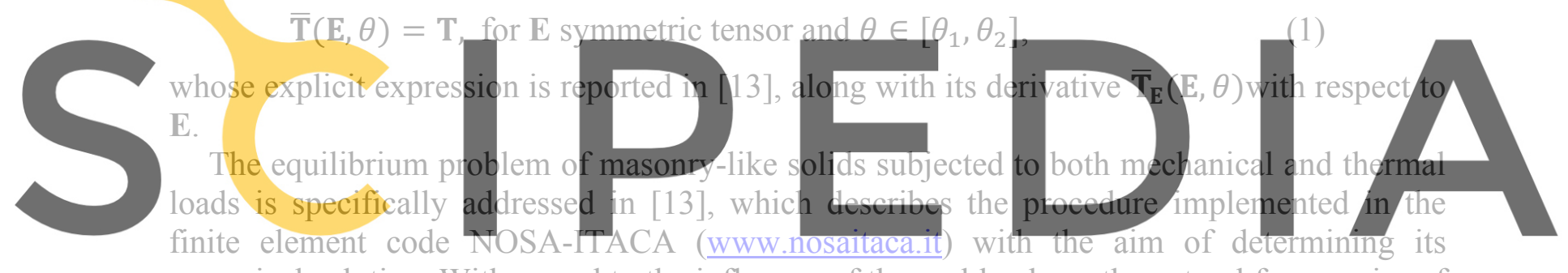
numerical solution. With regard to the influence of thermal loads on the natural frequencies of

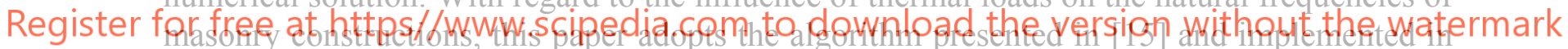

NOSA-ITACA, which enables calculating the frequencies and mode shapes of masonry

constructions while taking into account the presence of cracks due to mechanical and thermal loads. More precisely, given a masonry structure, discretized into finite elements, and given its materials properties, together with the kinematic constraints and loads (both mechanical and thermal), the algorithm is based on a linear perturbation about the solution to the equilibrium problem and calculates the frequencies of the cracked structures by taking into account the tangent stiffness matrix, which is symmetric and positive definite. The algorithm has proved to be able to reproduce the changes measured in the frequencies of masonry structures subjected to reinforcement operations, such as for example, the Mogadouro tower (Portugal) addressed in [16]. Also, the algorithm has been successfully used in [17, 18]to model the changes measured in the frequencies of two masonry towers in Lucca, likely related to seasonal thermal variations. For both the towers considered, frequencies tend to increase with increasing temperature, a trend which was also recognized in numerous experimental campaigns regarding ancient masonry towers $[6,8,10]$.

In the following section, we present some analyses conducted on two simple masonry arch models: the first (Model 1) is a round arch with a three-meter span, the second (Model 2) a 
masonry arch bridge spanning about $45 \mathrm{~m}$ and with a rise-to-span ratio of about $1 / 7$. The influence of temperature variations is examined with regard to both the static and the dynamic behaviour of these structures.

\section{MASONRY ARCHES SUBJECTED TO THERMAL LOADS}

\subsection{Model 1: A round arch}

Let us consider the masonry round arch shown in Figure 1, with a span of $3 \mathrm{~m}$ and thickness of about $20 \mathrm{~cm}$. It is discretized into 1200 thick shell elements (element 10 of the NOSA-ITACA library), for a total number of 7878 degrees of freedom. The masonry material, which is assumed to have null tensile strength and infinite compressive strength, has Young's modulus $E=310^{9} \mathrm{~Pa}$, Poisson's ratio $v=0.2$, mass density $\rho=1800 \mathrm{~kg} / \mathrm{m}^{3}$ and a linear coefficient of thermal expansion $\alpha=6 \cdot 10^{-6 \circ} \mathrm{C}^{-1}$. The mass density of the infill, whose thickness over the arch crown is $0.3 \mathrm{~m}$, is $\rho=1000 \mathrm{~kg} / \mathrm{m}^{3}$. The arch, with fixed springers, is first subjected to permanent loads (masonry and infill weights), and then to temperature variations $\Delta \theta$ ranging from $-15^{\circ} \mathrm{C}$ to $+15^{\circ} \mathrm{C}$. For the sake of comparison, the results obtained via the NOSA-ITACA code are validated against the commercial code MARC [19], using the constitutive law of low tensile materials and setting $E_{\mathrm{s}}=2.0 \cdot 10^{4} \mathrm{~N} / \mathrm{m}^{2}$ [16]. Figures 2 and 3 represent the plot of the normal force $N$ and the bending moment $M$ (assumed positive if the intrados is stretched) per unit width versus the arc length varying

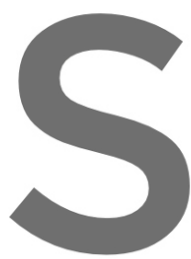
from 0 to $\pi R$, with $R=1$ $0^{\circ} \mathrm{C}$ is for the perman (continuous line) and cocenting and the linear elastic ca
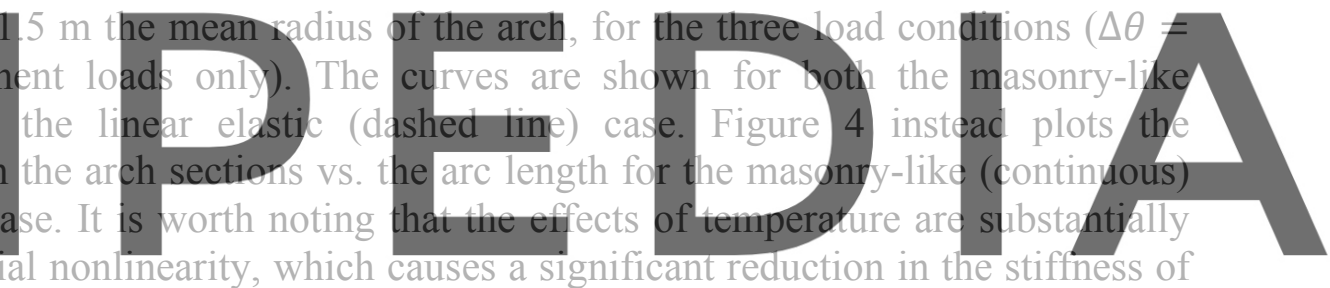
the arch sections, thus reducing the stresses in the arch with respect to the linear elastic case.
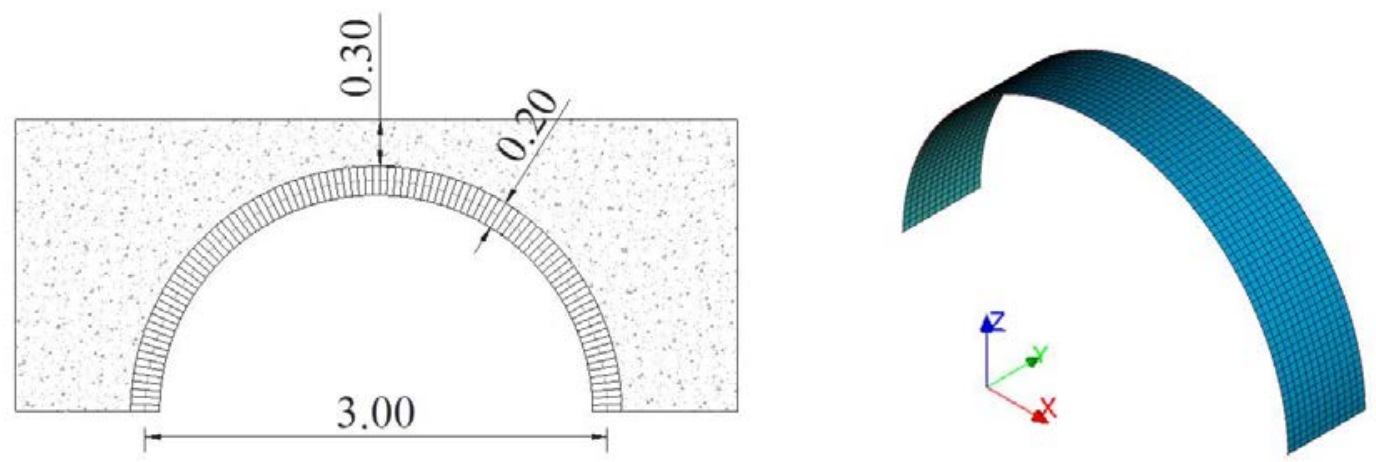

Figure 1: Model 1. Geometry and finite element mesh of the arch. 


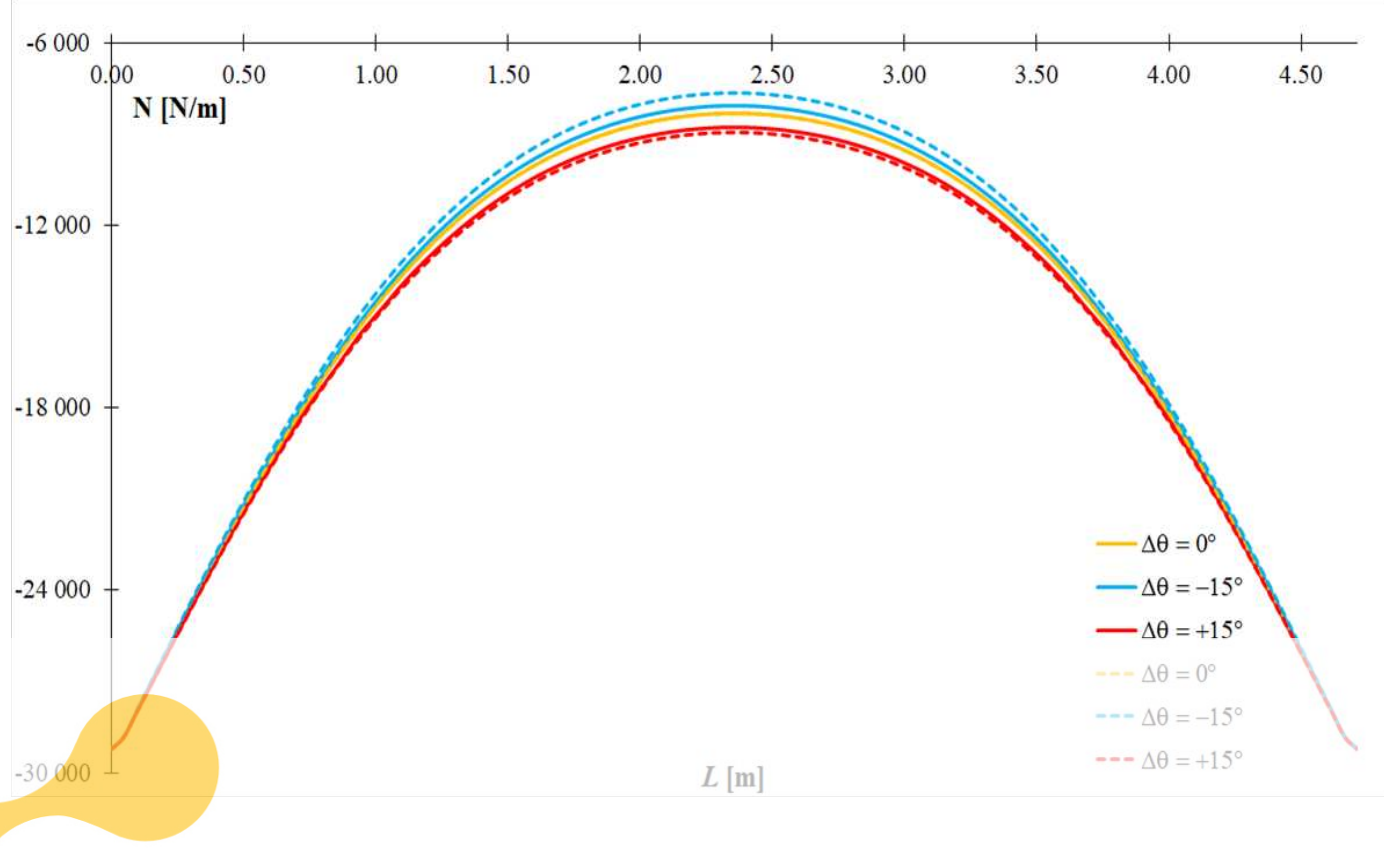

Figure 2: Model 1. Normal force per unit width $N[\mathrm{~N} / \mathrm{m}]$ versus the $\operatorname{arc}$ length $[\mathrm{m}]$ for $\Delta \theta=0^{\circ} \mathrm{C}$ (yellow), $\Delta \theta=$ $-15^{\circ} \mathrm{C}$ (cyan) and $\Delta \theta=+15^{\circ} \mathrm{C}$ (red); linear elastic material (dashed) and masonry-like material (continuous).
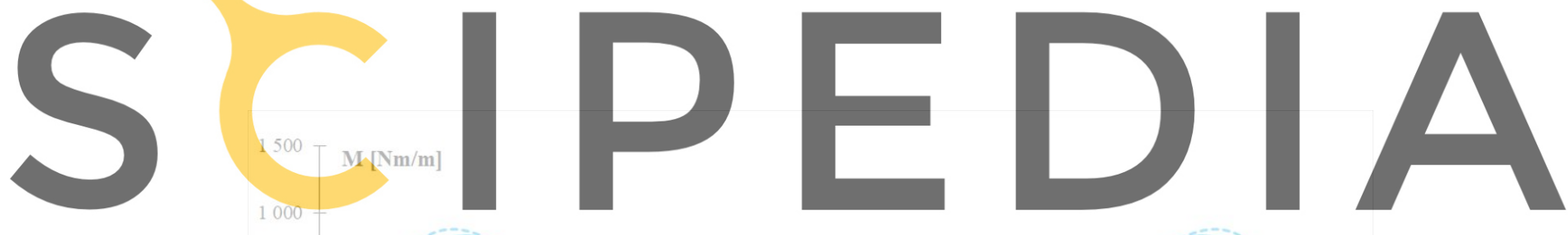

Register for freesat https/ huwww.scipedia.com to download the version without the watermark

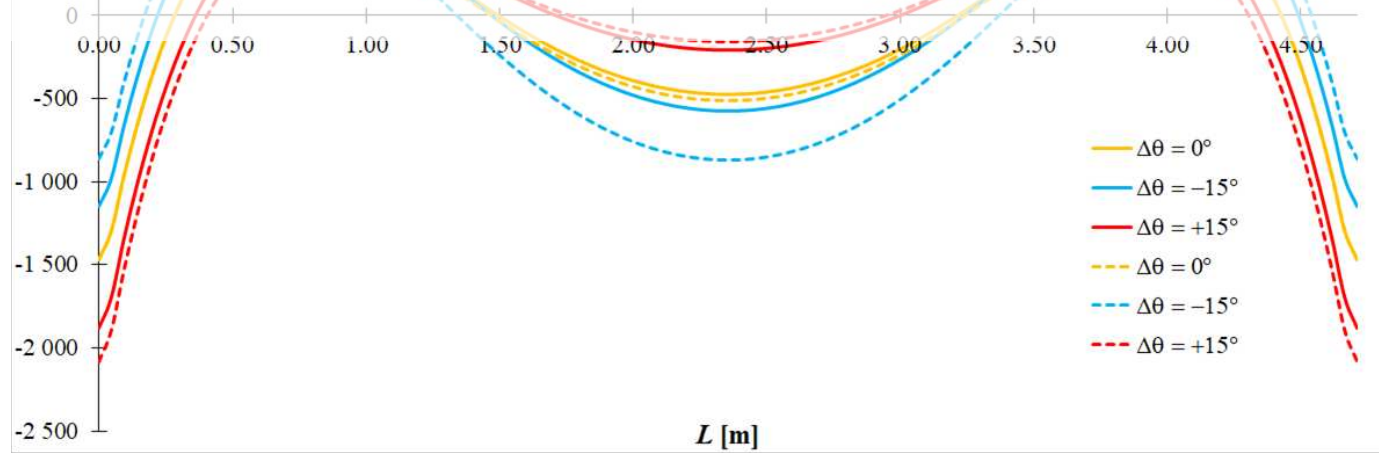

Figure 3.Model 1. Bending moment per unit width $M[\mathrm{~N} \mathrm{~m} / \mathrm{m}]$ versus the arc length $[\mathrm{m}]$ for $\Delta \theta=0^{\circ} \mathrm{C}$ (yellow), $\Delta \theta=-15^{\circ} \mathrm{C}$ (cyan) and $\Delta \theta=+15^{\circ} \mathrm{C}$ (red); linear elastic material (dashed) and masonry-like material (continuous). 


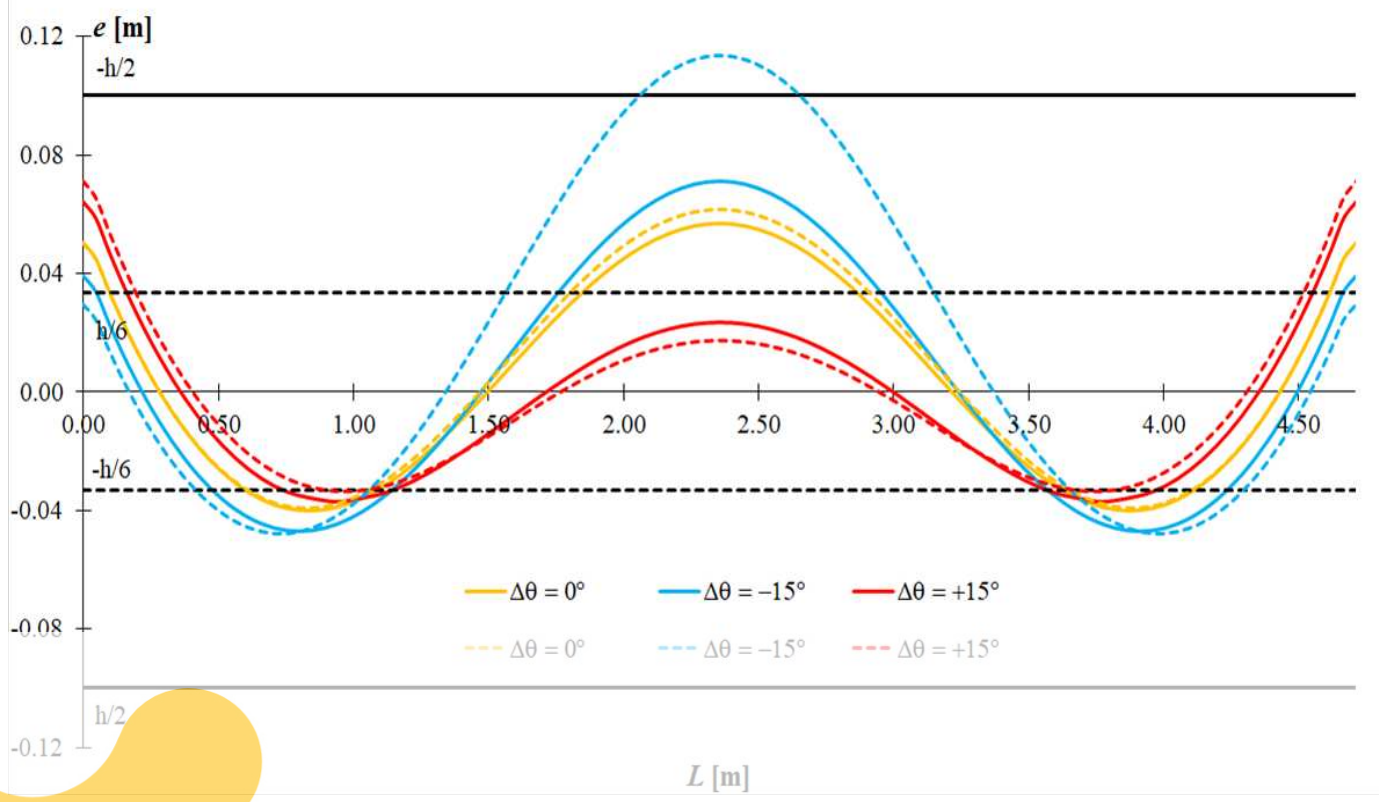

Figure 4. Model 1: Eccentricity $e[\mathrm{~m}]$ versus the arc length $[\mathrm{m}]$ for $\Delta \theta=0^{\circ} \mathrm{C}$ (yellow line), $\Delta \theta=-15^{\circ} \mathrm{C}$ (cyan) and $\Delta \theta=+15^{\circ} \mathrm{C}$ (red); linear elastic material (dashed) and masonry-like material (continuous).

To investigate how temperature variations affect the dynamic properties of the arch, the

procedure described in

in the linear elastic

permanent loads. The

fundamental frequency

the correlation between
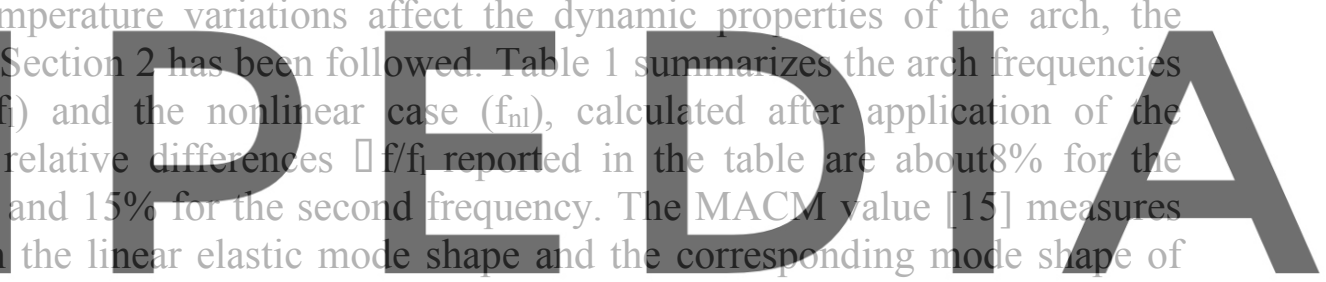

the cracked structure; values close to one indicate that, when transitioning from the linear to

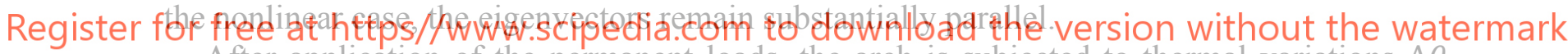

After application of the permanent loads, the arch is subjected to thermal variations $\Delta \theta$,

and the first four natural frequencies are calculated, as reported in Table 2. Figure 5 shows a

plot of the four frequencies vs. $\Delta \theta$. The second, third and fourth frequencies tend to increase with temperature. The curve of the first frequency, instead, shows a maximum for $\Delta \theta=0$ and decreases for positive values of $\Delta \theta$. In this case, as shown by the red curves in Figure 4 , increasing values of temperature tend to diminish the eccentricity in the central portions of the arch and increase the nonlinearity at the springings. The global result is a decrease inarch stiffness with respect to the horizontal displacements, which are involved particularly in the first mode shape (Figure 6). In general, mode shapes appear much less affected by temperature than frequencies, as proved by the values of the MACM indicator reported in Figure 6 (evaluated for each mode shape between the linear and the corresponding nonlinear eigenvector): all these values are close to one.

Finally, Table 3 shows, for different temperature increments, a comparison between the frequencies calculated by NOSA-ITACA and those calculated using MARC. The small differences at $\Delta \theta=0$ (on the order of 5\%) are attributable to the small tensile strength (not nil as in NOSA-ITACA) assumed in MARC. As shown in the table, despite the different 
constitutive equations adopted by the two codes, their results coincide after application of the thermal loads.

Table 1. Model 1. Comparison between linear $\left(f_{l}\right)$ and nonlinear case $\left(f_{n l}\right)$; permanent loads $([\square=0)$.

\begin{tabular}{ccccc}
\hline & $\begin{array}{c}\mathrm{f}_{\mathrm{l}} \\
{[\mathrm{Hz}]}\end{array}$ & $\begin{array}{c}\mathrm{f}_{\mathrm{nl}} \\
{[\mathrm{Hz}]}\end{array}$ & $\begin{array}{c}{\left[\mathrm{f} / \mathrm{f}_{1}\right.} \\
{[\%]}\end{array}$ & MACM \\
\hline Mode 1 & 14.704 & $\mathbf{1 3 . 5 4 5}$ & 7.88 & 0.999 \\
\hline Mode 2 & 31.991 & $\mathbf{2 7 . 0 4 4}$ & 15.46 & 0.991 \\
\hline Mode 3 & 57.138 & $\mathbf{5 1 . 4 0 9}$ & 10.03 & 0.993 \\
\hline Mode 4 & 73.048 & $\mathbf{6 4 . 4 0 1}$ & 11.84 & 0.976 \\
\hline
\end{tabular}

Table 2. Model 1. Effects of temperature variations on the first four mode shapes of the arch. $\square \mathrm{f}_{\mathrm{i}}(\mathrm{\square})=\left(\mathrm{f}_{\mathrm{i}}(\square \mathrm{Q})-\mathrm{f}_{\mathrm{i}}(0)\right) / \mathrm{f}_{\mathrm{i}}(0)$

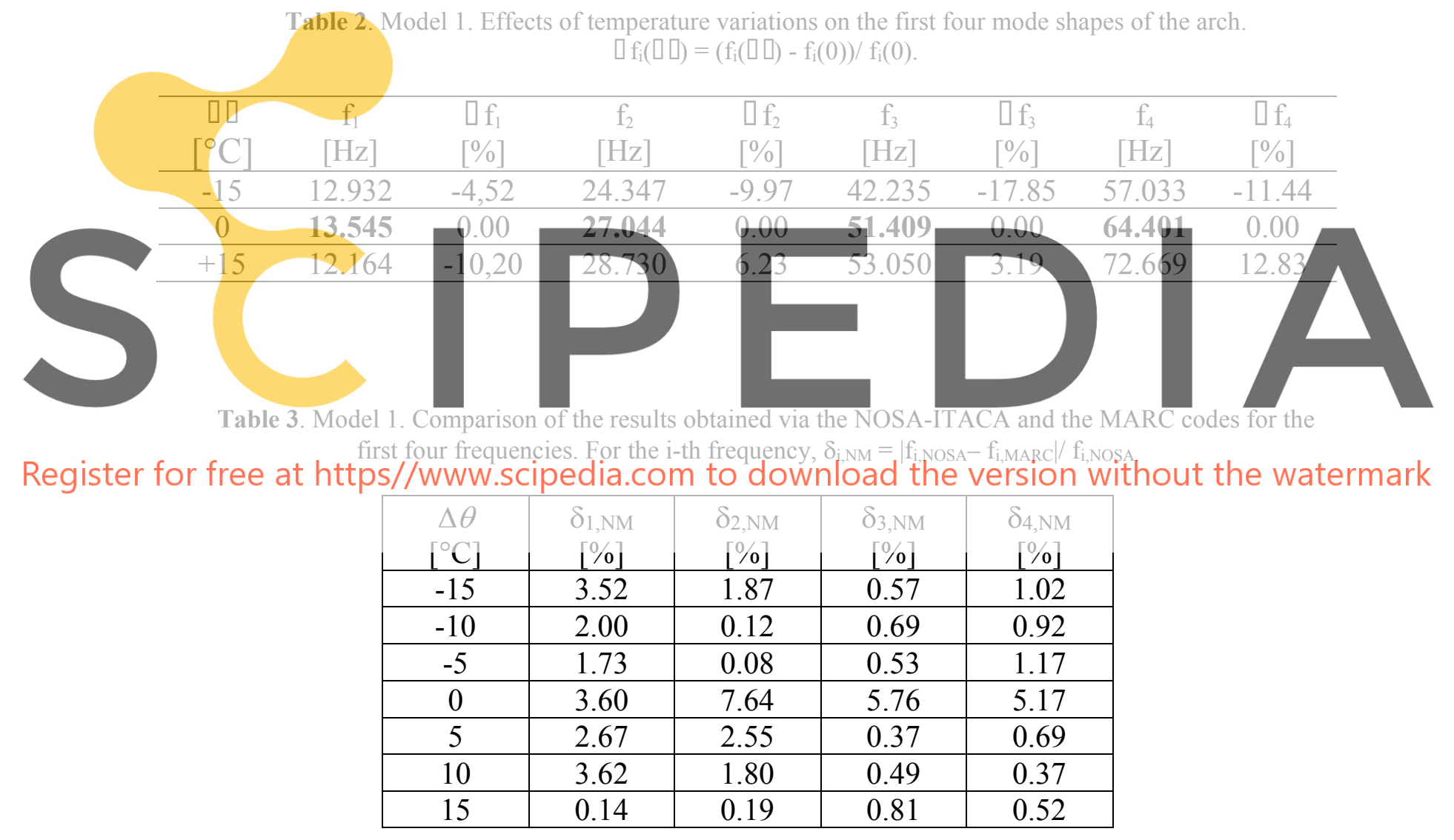



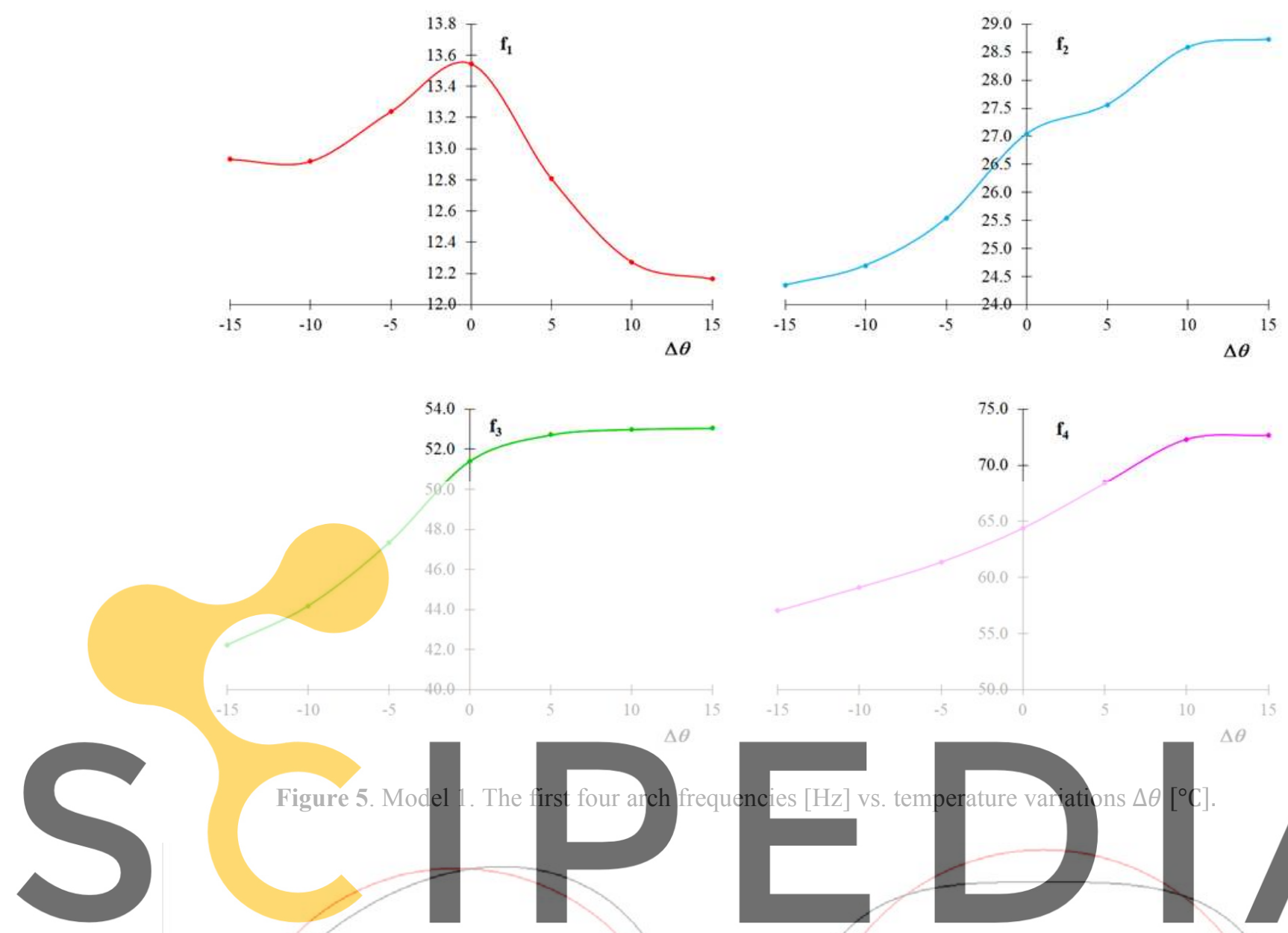

Register for free at https//www.scipedia.com to download the version without the watermark

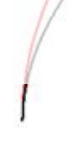

$$
\begin{aligned}
\text { Mode shape } 1 & \\
\operatorname{MACM}(\Delta \theta-0 \mathrm{C}) & =0.999 \\
\operatorname{MACM}\left(\Delta \theta=-15^{\circ} \mathrm{C}\right) & =0.996 \\
\operatorname{MACM}\left(\Delta \theta=+15^{\circ} \mathrm{C}\right) & =0.998
\end{aligned}
$$

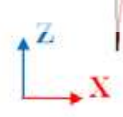

Mode shape 2

$\operatorname{MACM}(\Delta \theta=0 \mathrm{C})=0.991$
$\operatorname{MACM}\left(\Delta \theta=-15^{\circ} \mathrm{C}\right)=0.973$
$\operatorname{MACM}\left(\Delta \theta=+15^{\circ} \mathrm{C}\right)=0.997$
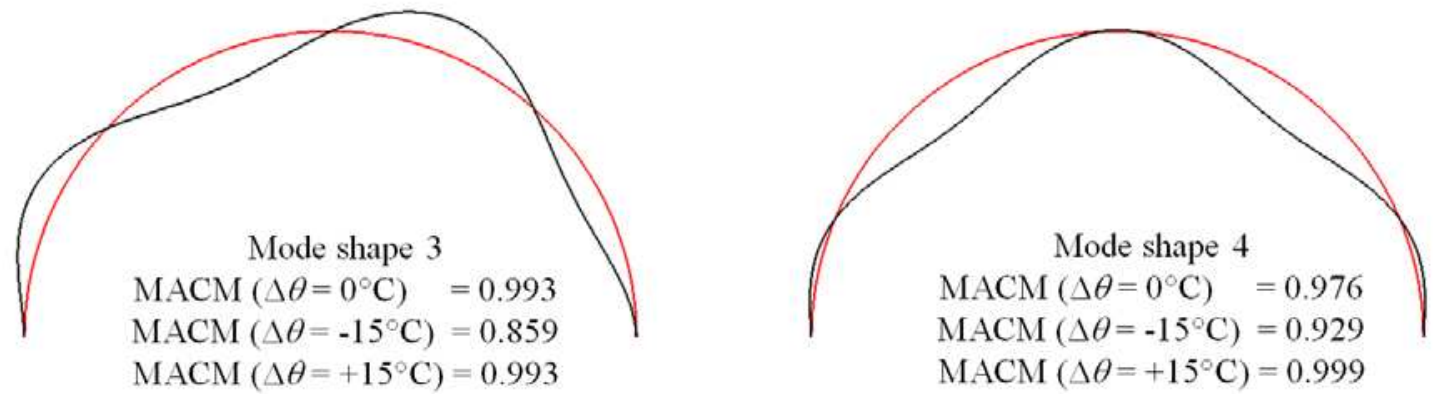

Figure 6. Model 1. The first four mode shapes of the arch. 


\subsection{Model 2: A masonry arch bridge}

Let us consider the masonry arch bridge shown in Figure 7, with a length of $44 \mathrm{~m}$, rise of about $6 \mathrm{~m}$ and constant thickness of $1.5 \mathrm{~m}$. It is discretized into 2160 thick shell elements, for a total number of 13650 degrees of freedom. The masonry properties are: Young's modulus $E$ $=410^{9} \mathrm{~Pa}$, Poisson's ratio $v=0.2$, mass density $\rho=2000 \mathrm{~kg} / \mathrm{m}^{3}$ and linear thermal expansion coefficient $\alpha=1 \cdot 10^{-5 \circ} \mathrm{C}^{-1}$. The mass density of the infill, whose thickness over the arch crown is $0.4 \mathrm{~m}$, is $\rho=2000 \mathrm{~kg} / \mathrm{m}^{3}$. The arch, with fixed springers, is first subjected to permanent loads (masonry and infill weights) and then to temperature variations $\Delta \theta$ ranging from $-10^{\circ}$ to $+15^{\circ}$.
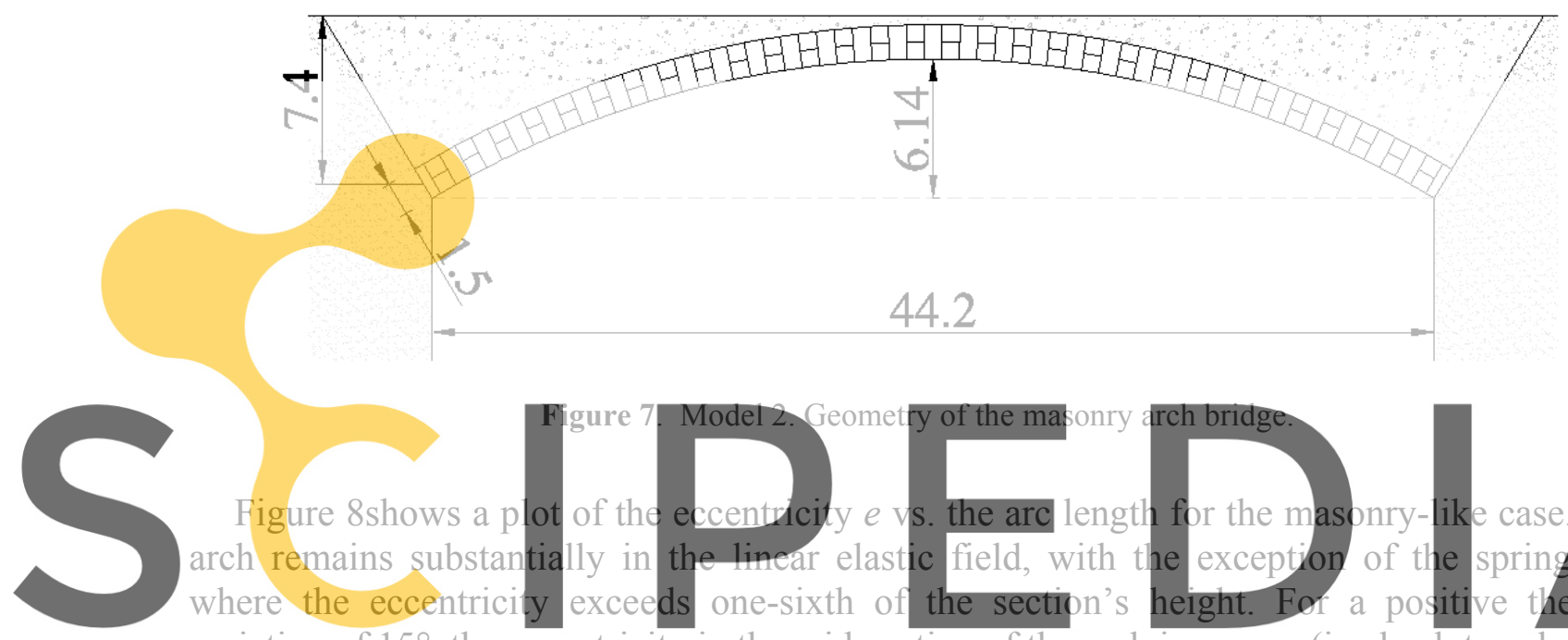

variation of $15^{\circ}$, the eccentricity in the mid-section of the arch increases (in absolute value) by Register for free at hassing from -9 cm to $13 \mathrm{~cm}$. Correspondingly the arch's mid section rises by about $0.5 \mathrm{~cm}$. For $\Delta \theta=-10$, representing winter conditions, the eccentricity in the midsection falls from $-9 \mathrm{~cm}$ to $-6.8 \mathrm{~cm}(24 \%)$, and the arch crown undergoes a lowering of about $2.6 \mathrm{~cm}$. Thus, the total displacement of the arch mid-section produced by the considered thermal variations is about $3 \mathrm{~cm}$. These data are in agreement with the experimental evidence, as described in [2], which reports on different cases of masonry arch bridges that present lowering of the crown during winter and its rising during summer. Comparison between Figures 4 and 8 also highlights the role of the span-to-rise ratio on the arches' static behaviour. In fact, Model 1 and Model 2 exhibit very different behaviours even for permanent loads, with opposite signs of the eccentricity.

Regarding the influence of thermal variations on the bridge's modal properties, Table 4 reports the bridge frequencies for different temperature increments. Frequencies at $\Delta \theta=0$ are calculated for the permanent loads only. The trend evident in the table is similar to that found for masonry towers: all frequencies tend to increase with increasing temperatures. The frequency variations range from $11 \%$ for the fundamental frequency to $0.16 \%$ for the third frequency. As a general remark, the frequency values seem to be more influenced by positive values of $\Delta \theta$ : this trend is clearly shown by Figure 9, where the graphs of the four frequencies are plotted vs. temperature increments. As shown in Figure 8, positive values of $\Delta \theta$ tend to 
reduce the eccentricity at the springers, which represent the only portions of the arch in the nonlinear field, and thus the structure quickly approaches linear elastic behaviour. Finally, Figure 9 shows the arch's first four mode shapes. As for Model 1, mode shapes are less affected by temperature than frequency, and the values of the MACM indicator (evaluated for each mode shape between the linear and the corresponding nonlinear eigenvector) are all close to one.
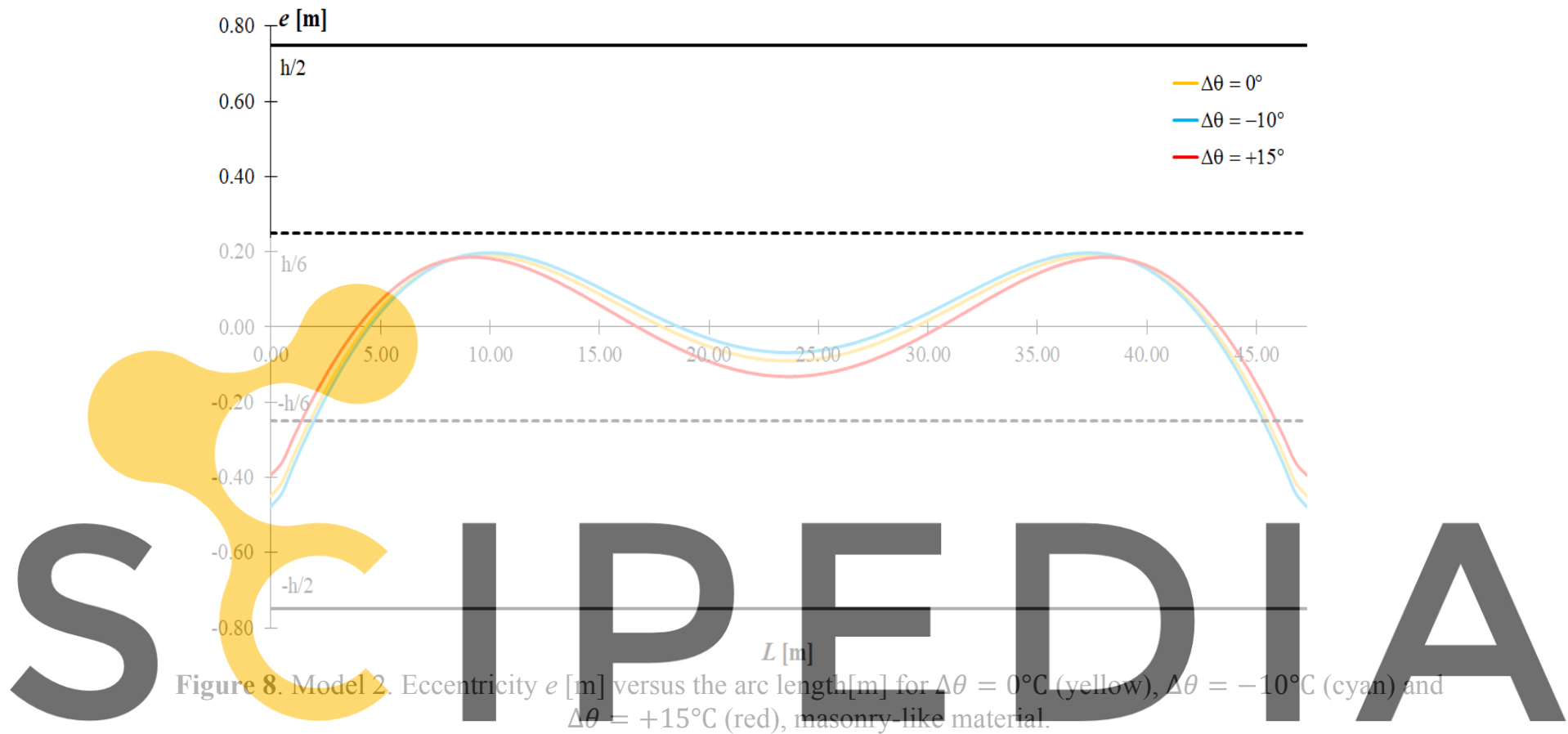

Register for free at https//www.scipedia.com to download the version without the watermark Effects of temperature variations on the arch's first four frequencies;

$\square \mathrm{f}_{\mathrm{i}}(\square \mathrm{Q})=\left(\mathrm{f}_{\mathrm{i}}(\square \mathrm{Q})-\mathrm{f}_{\mathrm{i}}(0)\right) / \mathrm{f}_{\mathrm{i}}(0)$.

\begin{tabular}{|c|c|c|c|c|c|c|c|c|}
\hline $\begin{array}{c}\mathrm{CD} \\
{\left[{ }^{\circ} \mathrm{C}\right]}\end{array}$ & $\begin{array}{c}\mathrm{f}_{1} \\
{[\mathrm{~Hz}]}\end{array}$ & $\begin{array}{l}\mathrm{f}_{1} \\
{[\%]}\end{array}$ & $\begin{array}{c}\mathrm{f}_{2} \\
{[\mathrm{~Hz}]}\end{array}$ & $\begin{array}{c}\mathrm{f}_{2} \\
{[\%]}\end{array}$ & $\begin{array}{c}\mathrm{f}_{3} \\
{[\mathrm{~Hz}]}\end{array}$ & $\begin{array}{l}\mathrm{f}_{3} \\
{[\%]}\end{array}$ & $\begin{array}{c}\mathrm{f}_{4} \\
{[\mathrm{~Hz}]}\end{array}$ & $\begin{array}{c}\mathrm{f}_{4} \\
{[\%]}\end{array}$ \\
\hline-10 & 1.435 & -1.37 & 2.758 & -1.71 & 3.624 & -0.60 & 4.813 & -1.51 \\
\hline-5 & 1.444 & -0.76 & 2.788 & -0.64 & 3.645 & -0.03 & 4.869 & -0.37 \\
\hline 0 & 1.455 & 0.00 & 2.806 & 0.00 & 3.646 & 0.00 & 4.887 & 0.00 \\
\hline+5 & 1.519 & 4.40 & 2.885 & 2.82 & 3.647 & 0.03 & 4.997 & 2.25 \\
\hline+10 & 1.535 & 5.50 & 2.900 & 3.35 & 3.648 & 0.05 & 5.016 & 2.64 \\
\hline+15 & 1.619 & 11.27 & 3.018 & 7.56 & 3.652 & 0.16 & 5.198 & 6.36 \\
\hline
\end{tabular}



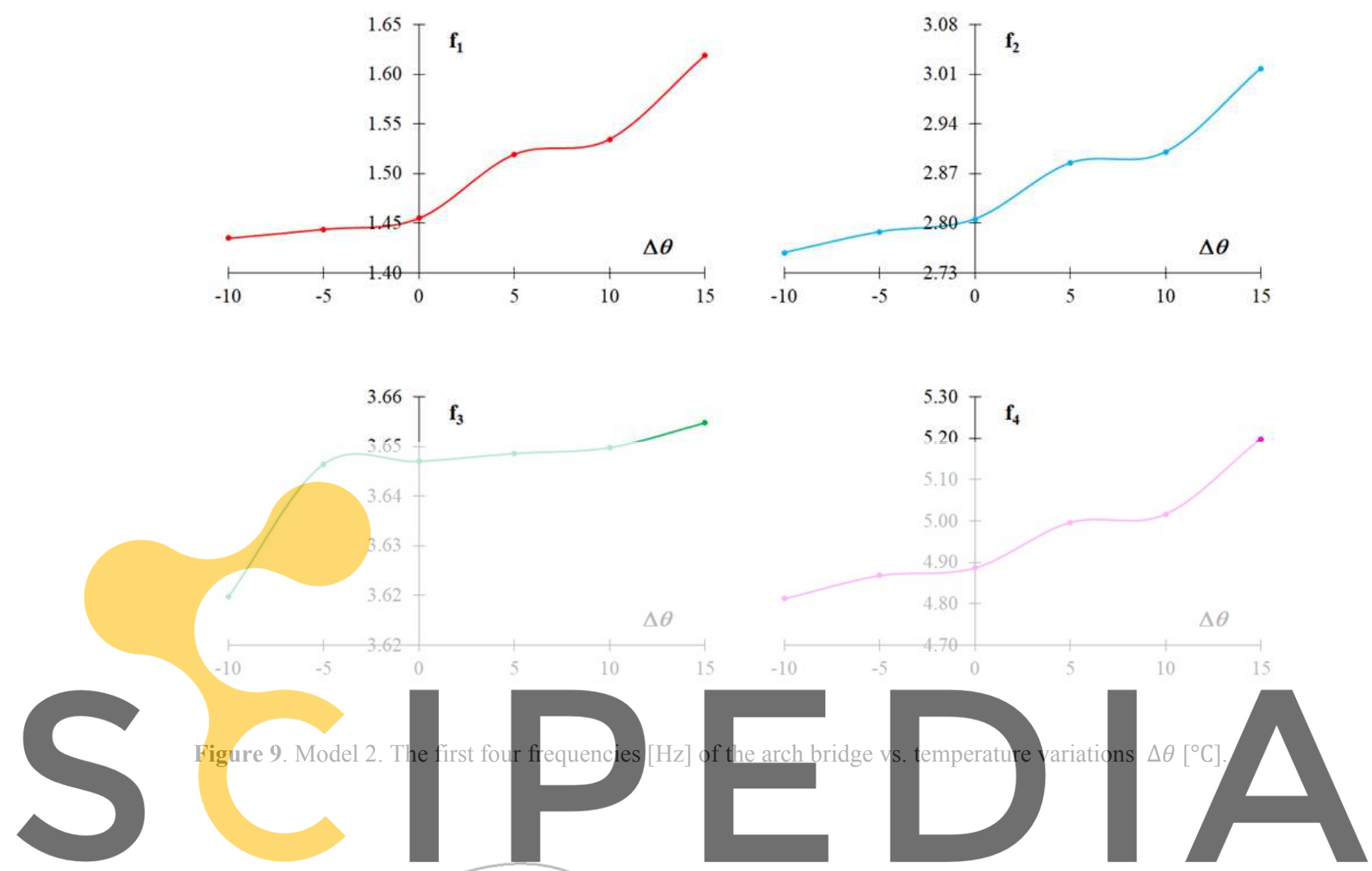

Register for free at https//www.scipedia.com to download the version without the watermark

Mode shape 1

$$
\begin{aligned}
& \operatorname{MACM}\left(\Delta \theta=0^{\circ} \mathrm{C}\right)=0.994 \\
& \operatorname{MACM}\left(\Delta \theta=-10^{\circ} \mathrm{C}\right)=0.998 \\
& \operatorname{MACM}\left(\Delta \theta=+15^{\circ} \mathrm{C}\right)=0.998
\end{aligned}
$$

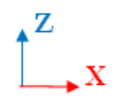

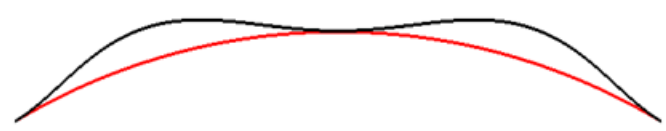

Mode shape 3

$\operatorname{MACM}\left(\Delta \theta=0^{\circ} \mathrm{C}\right) \quad=0.985$

$\operatorname{MACM}\left(\Delta \theta=-10^{\circ} \mathrm{C}\right)=0.986$

$\operatorname{MACM}\left(\Delta \theta=+15^{\circ} \mathrm{C}\right)=0.992$

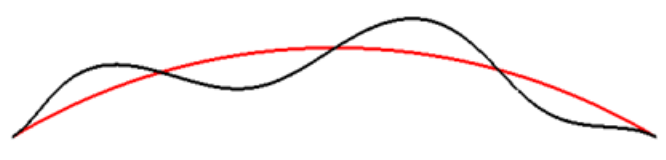

Mode shape 4

$\operatorname{MACM}\left(\Delta \theta=0^{\circ} \mathrm{C}\right) \quad=0.981$

$\operatorname{MACM}\left(\Delta \theta=-10^{\circ} \mathrm{C}\right)=0.981$

$\operatorname{MACM}\left(\Delta \theta=+15^{\circ} \mathrm{C}\right)=0.996$

Figure 10. Model 2. The first four mode shapes of the arch bridge. 


\section{CONCLUSIONS}

The paper presents some analyses conducted via the NOSA-ITACA code to assess the influence of temperature variations on the static and dynamic behaviour of masonry structures. The paper extends previous results obtained by the authors on masonry towers subjected to thermal loads.

The case studies analysed in the paper are a round arch and an arch bridge, two structural elements very common in the worldwide architectural heritage. The effects of thermal loads are discussed in terms of the consequent variations in eccentricities and modal properties, with particular regard to natural frequencies. In both cases, when the masonry's scarce capacity to withstand tensile stresses is taken into account (zero or very small tensile strength), thermal loads do not seem to significantly affect the static equilibrium of the arches. In fact, cracking due to the thermal strains causes a reduction in structural stiffness, with consequent mitigation of the stresses induced by the thermal variations. These changes in stiffness in turn affect the arches' modal properties, thus giving rise to significant changes in their natural frequencies.

The numerical results shown in the paper are in agreement with similar outcomes presented in the limited literature available on the topic. Comparisons between numerical and experimental results would be necessary to validate and corroborate the numerical simulations. Experimental tests aimed at investigating the influence of temperature variations on the structural behaviour of masonry arches are being planned for the near future.

\section{Acknowledgements.}

This research was partially funded by the Fondazione Cassa di Risparmio di Lucca (Lucca Savings Bank Foundation) within the framework of the project "SOUL - Urban Seismology in the Historic Centre of Lucca", 2019-2022. This support is gratefully acknowledged.

\section{REFERENCES}

[1] Timoshenko, S.P. and Goodier, J.N. Theory of elasticity, third Edition, McGraw-Hill Book Company (1970).

[2] Guidi, C. Influenza della temperatura sulle costruzioni murarie. Atti della Reale Accademia delle Scienze di Torino (1906) 319-330.

[3] Taliercio, A. and Binda, L. The Basilica of San Vitale in Ravenna: Investigation on the current structural faults and their mid-term evolution. Journal of Cultural Heritage (2008) 8: 99-118.

[4] Blasi, C. and Coisson, E. The effects of temperature on historical stone masonry structures. Structural Analysis of Historic Construction: Preserving Safety and Significance (2008) 1271-1276.

[5] Talebinejad, I., Fischer, C., and Ansari, F. A hybrid approach for safety assessment of the double span masonry vaults of the Brooklyn Bridge. Journal of Civil Structural Health Monitoring (2011) 1(1-2): 3-15. 
[6] Azzara, R.M., De Roeck, G., Girardi, M., Padovani, C., Pellegrini, D. and Reynders, E. The influence of environmental parameters on the dynamic behaviour of the San Frediano bell tower in Lucca. Engineering Structures (2018) 156: 175-187.

[7] Dal Cin, A. and Russo, S. Evaluation of static and dynamic long-term structural monitoring for monumental masonry structure. Journal of Civil Structural Health Monitoring (2019) 9.2: 169-182.

[8] Gentile, C., Guidobaldi, M. and Saisi, A. One-year dynamic monitoring of a historic tower: damage detection under changing environment". Meccanica (2016) 51(11): 2873-89.

[9] Gentile, C., Ruccolo, A. and Canali, F. Long-term monitoring for the condition-based structural maintenance of the Milan Cathedral. Construction and Building Materials (2019) 228: 1171012019.

[10] Ramos, L.F., L. Marques, L:, Lourenco, P.B., De Roeck, G., Campos-Costa, A. and Roque, J. Monitoring historical masonry structures with operational modal analysis: Two case studies”, Mech. Syst. Signal Process (2010) 24:1291-1305.

[11] Elyamani, A., Caselles, O., Roca, P. \& Clapes, J. Integrated dynamic and thermography investigation of Mallorca Cathedral. Mediterranean archaeology \& archaeometry (2018) 18(1): 221-236.

[12] DelPiero, G. Constitutive equation and compatibility of the external loads for linearlyelastic masonry-like materials, Meccanica (1989) 24: 150-162.

[13] Lucchesi, M., Padovani, C., Pasquinelli, G. and Zani, N. Masonry constructions: mechanical models and numerical applications. Lecture Notes in Applied and Computational Mechanics, Springer-Verlag, (2008).

[14] Padovani, C., Pasquinelli, G., and Zani, N. A numerical method for solving equilibrium problems of no-tension solids subjected to thermal loads. Computer methods in applied mechanics and engineering (2000) 190.1-2: 55-73.

[15] Girardi, M., Padovani, C., and Pellegrini, D. Modal analysis of masonry structures, Mathematics and Mechanics of Solids (2019) 24(3): 616-636.

[16] Pellegrini, D., Girardi, M., Lourenço, P. B., Masciotta, M. G., Mendes, N., Padovani, C. And Ramos, L. F. Modal analysis of historical masonry structures: Linear perturbation and software benchmarking. Construction and Building Materials (2018) 189:12321250 .

[17] Azzara, R.M., Girardi, M., Iafolla, V., Padovani, C. and Pellegrini, D. Long-term dynamic monitoring of medieval towers. Front. Built Environ. - Earthquake Engineering, (2020), https://doi.org/10.3389/fbuil.2020.00009.

[18] Girardi, M., Padovani, C., and Pellegrini, D. Effects of the stress field on the dynamic properties of masonry bell towers. AIMETA 2017 - Proceedings of the 23rd Conference of the Italian Association of Theoretical and Applied Mechanics (2017) 3: 216-229.

[19] Marc 2014 Volume A: theory and user information. Marc \&Mentat (2014) -Marc \&Mentat Docs.

[20] Proske, D. and Van Gelder, P. Safety of historical stone arch bridges. Springer Science \& Business Media(2009). 